\title{
Research on the Development and Application of Three-dimensional Teaching Resources for the Professional Core Curriculum of Civil Engineering Specialty
}

\author{
Xiuyan Zhang ${ }^{1}$, Huiqin Yang ${ }^{1}$, Zhaojun Ren ${ }^{1}$, Song Zhou ${ }^{1}$, Xine Zhang ${ }^{2}$ \\ 1.Binzhou Polytechnic, Binzhou 256603, China 317698397@qq.com \\ 2.Transportation Administration of Gaotang ,Gaotang252800 , Shandong Province,China \\ 709064576@qq.com
}

Keywords: Internet; Virtual technology; Entity engineering; Three-dimensional; Teaching resources

\begin{abstract}
For civil engineering specialty, this article expounds a kind of resource development thinking that is based on the combination of Internet and virtual technology. And the development and application of professional core curriculum teaching resources are practiced. In the process of research, we developed curriculum resources using vitual technology and built a Large-scale online open course platform. The teaching mode of "virtuality and reality combination, online and offline" and the learning mode of "theory with practice integration, in class and outside" were applied. And we practiced "networked timely tracking and evaluation”.
\end{abstract}

\section{Introduction}

The following is indicated in the notice of the ministry of education on the development plan for education informationization (2011-2020): it is of great significance to improve the quality of education, promote education fairness, and build a learning society and the human resources powers through promoting the popularization and sharing high-quality education resources, promoting the information technology and education teaching depth fusion, and realizing the omnibearing education thought, idea, method and means. The teaching resources of building engineering construction have the following problems. Firstly,in the current "Internet +" mode, the degree of informationization of teaching resources is relatively low. It is not suitable for the teaching mode of "online and offline". Secondly, professional courses are not developed in the same entity engineering. This causes that students only can obtain one-sided and fragmentary knowledgy. Thirdly, the long construction period of the construction entity engineering cannot meet the students' training objectives. Construction engineering students have low ability to accept the teaching resources, so the teaching resources cannot meet the needs of students well. It is relatively low to cultivate students' vocational ability of informatization technology. This is not suitable for the application of information technology in modern rapid development. The teachers in the school are relatively weak in the use of information technology, and cannot meet the construction requirements of digital campus on teaching resources. It become an urgent problem to solve to innovate teaching resources development model of building engineering construction professionals, to develop modern informatization teaching resources under "Internet +", and to seek to teaching resources that adapt to the ability and level of acceptance of construction engineering students.

\section{Reform objectives and main content}

It is the main goal of the reform to develop the teaching resources suitable for the students of civil engineering.

\subsection{The teaching reform idea of "Internet + entity engineering" is adopted}

The project of building entity engineering is developed on the Internet. We pay attention to the continuity of professional teaching. Four kinds of typical structure engineering are selected in 
practice, which are brick concrete structure, frame structure, shear wall structure and frame - shear wall structure. They are applied in students' dormitories in school, teaching buildings, teachers' houses and office buildings. Meanwhile, we developed curriculum resources using using BIM, AR, VR and other virtual technologies and built a Large-scale online open course platform. The teaching mode of "virtuality and reality combination, online and offline" and the learning mode of "theory with practice integration, in class and outside" were applied. And we practiced "networked timely tracking and evaluation". This reflected that teaching reform idea of "Internet + entity engineering" is adopted, as shown in Fig. 1.

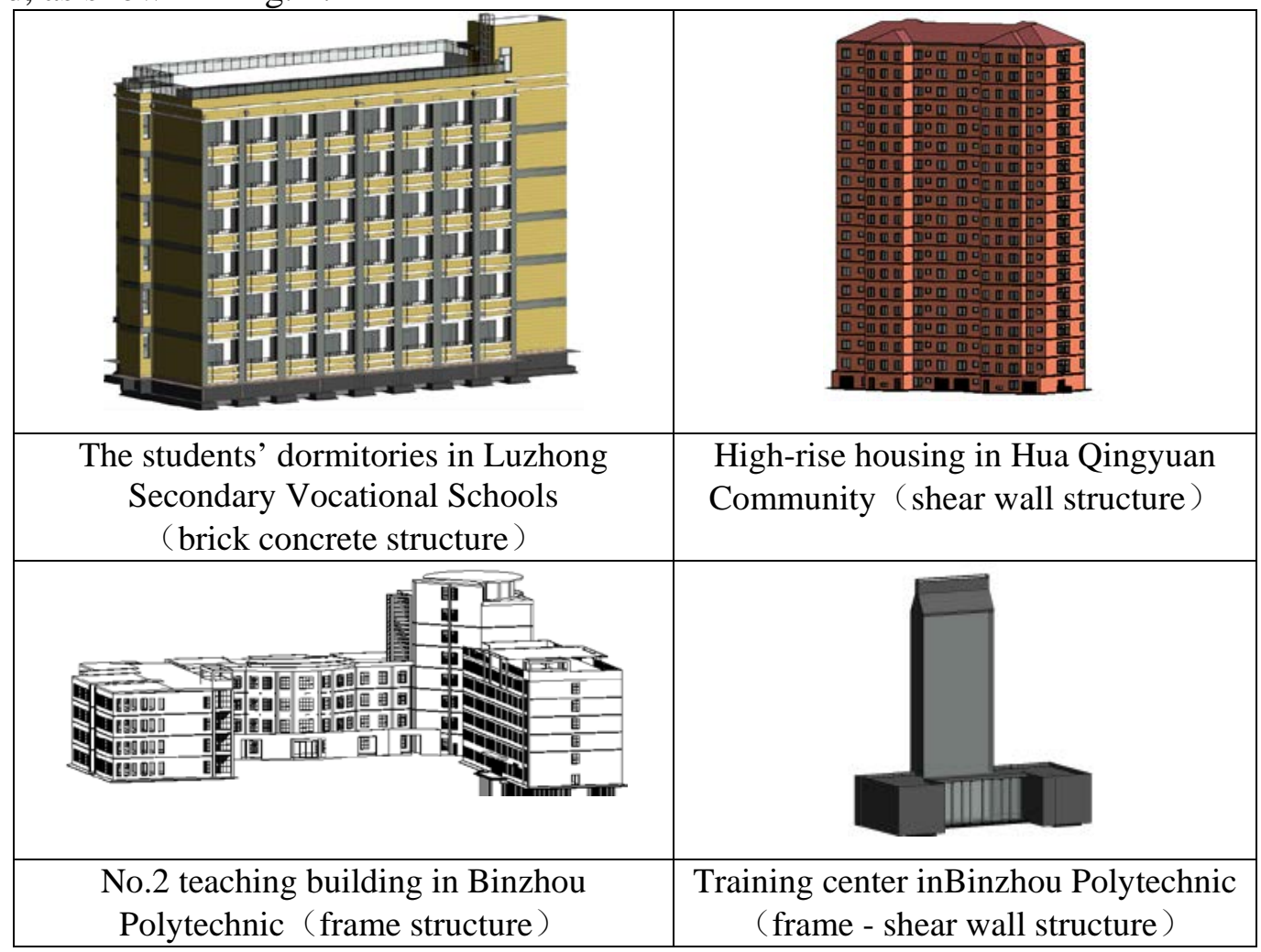

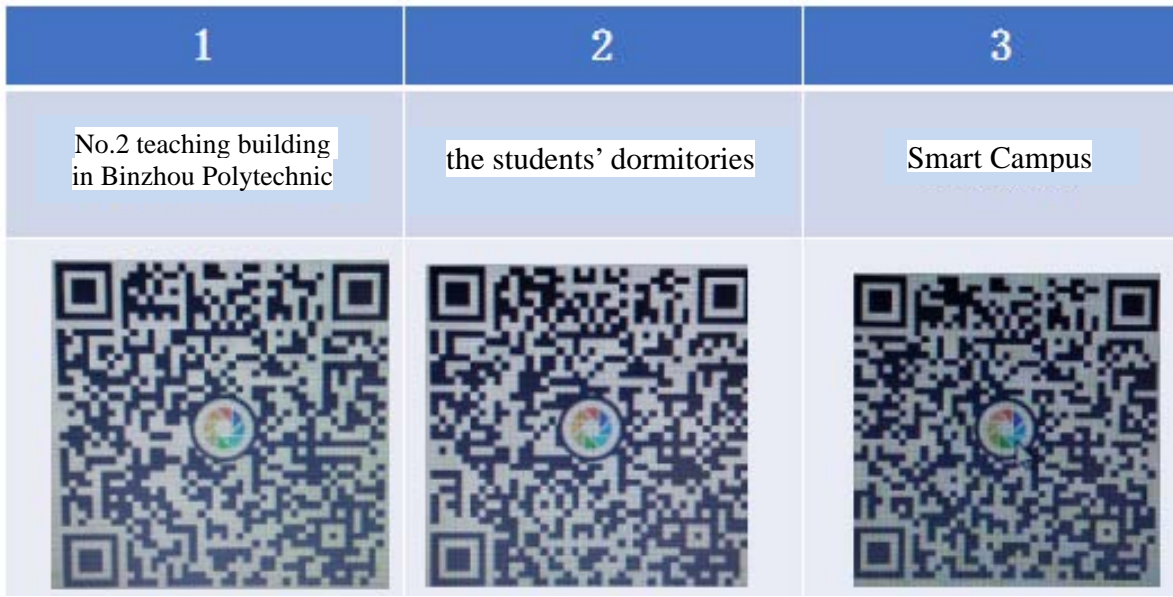

Fig. 1 Internet + Entity engineering + Virtual reality

\subsection{The teaching mode of "virtuality and reality combination, online and offline" is adopted}

The teaching mode of "virtuality and reality combination, online and offline" is shown in Fig.2 


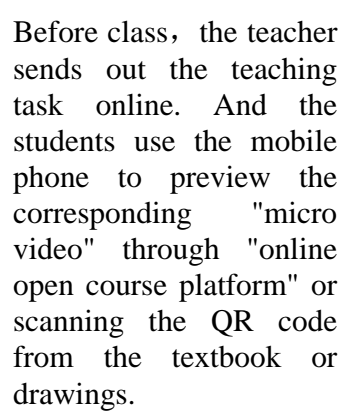

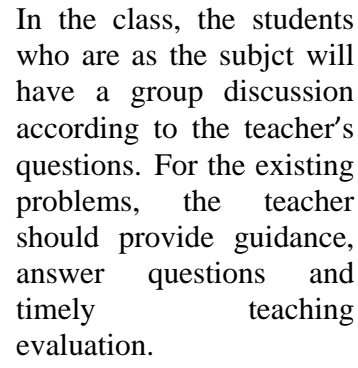

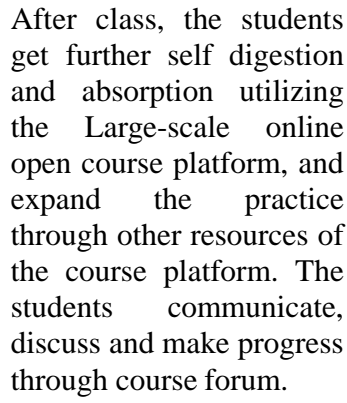

Fig.2 The teaching mode of "virtuality and reality combination, online and offline"

\subsection{The learning mode of "theory with practice integration, in class and outside" is applied.}

Before class, the students preview the assignments on the platform. They can use the form of "scan" to make use of the QR code on the drawing to link the drawings, atlases, the scene pictures and videos. In the class, they disscuss the questions and learn the correspongding knowledge according to the teacher's guidance. After class, the students complete the extension work and upload teaching platform and the teacher will provide the real-time evaluation. The students can browse the feedback information and evaluation at any time. These content lead to the learning mode of "theory with practice integration, in class and outside".

\section{Implement achievements}

Through the implementation of the above content, 3 courses in provincial high-quality goods resource sharing and 1 course in college boutique resources sharing have been completed. Two courses in provincial high-quality goods resource sharing are in the process of declaring construction. We have written 5 digital textbooks based on entity engineering and published 5 educational reform papers of this achievement. We won 18 award in the relatively projects and 6 awards in the skills competition.

The number of students in Luzhong Secondary Vocational Schools attending college entrance exam is 7 in 2012. This number increases to 52 in 2017. Undergraduate enrollment is up to 29 in 2015. Student employment has been increasing for several years in Luzhong Secondary Vocational Schools. Their rate of employment ranges from $80 \%$ to $98.3 \%$ and the professional counterpart employment rate is $92.2 \%$. The rate of employment in Binzhou Polytechnic ranges from $85 \%$ to $97 \%$. The students' overall interest in learning is improved. The information level of the students has been obviously improved. We Win the national and provincial awards in the skills competition. Through the development of informationization teaching resources combining with "Internet + entity engineering", the teachers' ability of developing teaching resources through the information technology is improved. The teachers won the provincial first prize and third prize in the Shandong provincial information teaching contest respectively and they taught in the professional leaders open classes twice in the city's secondary vocational schools. The teachers' ability to teach has been affirmed in all aspects of society. In the process of project construction, the promotion of teaching resources has also greatly improved the growth of teachers. The director of the project has successively obtained the honors of the outstanding teacher in the country and the grade teacher in Shandong province. In 2017, the director was promoted to a senior lecturer, and lead the building construction team to obtain the title of the excellent teaching team at the provincial level. The cost teaching and research office of Binzhou Polytechnic obtains the title of the excellent teaching team at the provincial level. For the effect of teacher training, the employment survey is carried out for the graduates. The employers have given a high degree of evaluation to the quality of the training. 


\section{Characteristics and innovation}

\subsection{Characteristics}

The first charateristic is the introduction of "Internet+" and "entity engineering". The convenience of resource sharing, the visualization of abstract problems and the simplification of complex problems provide convenience for "teaching" and "learning". The introduction of "entity engineering" to teaching always plays a positive role in the cultivation of students' construction post ability.

The second charateristic is the development the three-dimensional "micro courses" of "Internet + entity engineering". The "intelligent information technology" is introduced into the development of teaching resources. Based on the solid engineering, the digital teaching resources are made and the teaching resources are stereoscopic.

The third charateristic is that the teaching mode of "online and offline" based on the large-scale online open course platform and online resources are adopted.

\subsection{Innovation}

The first innovation is the idea of teaching reform of "Internet + entity engineering". Four kinds of typical structure engineering are selected in practice, which are brick concrete structure, frame structure, shear wall structure and frame - shear wall structure. They are applied in students' dormitories in school, teaching buildings, teachers' houses and office buildings. It is shown in Fig.3.Meanwhile, we developed curriculum resources using using BIM, AR, VR and other virtual technologies and built a Large-scale online open course platform. The teaching mode of "virtuality and reality combination, online and offline" and the learning mode of "theory with practice integration, in class and outside" were applied. And we practiced "networked timely tracking and evaluation".

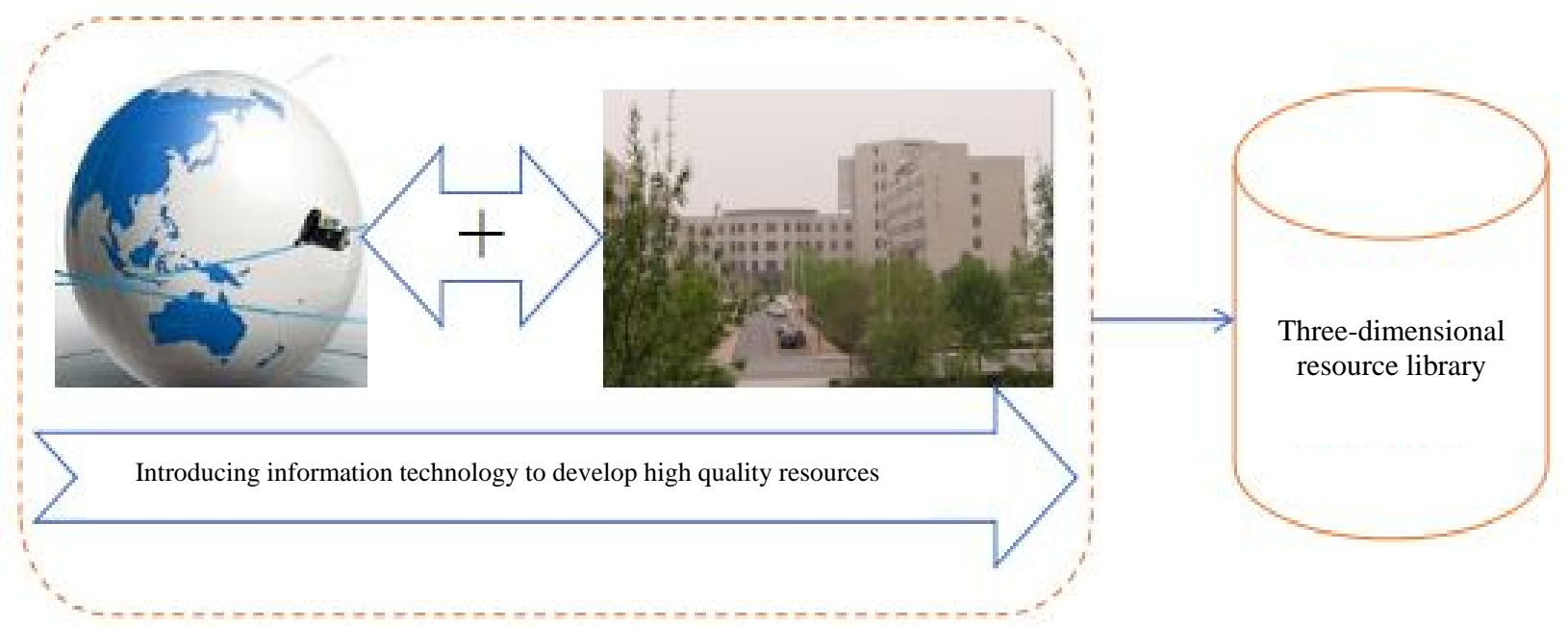

Fig.3 Internet + entity engineering

The second innovation is the teaching mode of "virtuality and reality combination, online and offline”. Using BIM, AR, VR and other virtual technology, virtual reality simulation of 4 selected projects is carried out, and detailed animation and key nodes are formed to form three-dimensional animation models, forming virtualized three-dimensional teaching resources. The whole process of engineering construction containing feasibility research, bidding, construction and completion acceptance is tracked. The data of entity engineering drawings are collected. And the construction process is recorded by taking pictures and videos. These work forms substantialized teaching resources. Through Internet, virtual and physical engineering resources are linked together, a teaching main line is formed. With building large-scale online open course platform, a teaching mode of "virtual reality combination, online and offline" is formed.

The third innovation is the learning mode of "theory with practice integration, in class and outside". Based on the digital textbook of entity engineering, we select 583 typical knowledge 
points to upload network platform, forming QR code including theoretical knowledge and practical skills. Before class, the students previewed the teacher's homework on the platform. In the class, they disscuss the questions and learn the correspongding knowledge according to the teacher's guidance. After class, the students complete the extension work and upload teaching platform and the teacher will provide the real-time evaluation. The students can browse the feedback information and evaluation at any time. These content lead to the learning mode of "theory with practice integration, in class and outside”.

\section{Popularization and Application}

The curriculum development group participates in compilation of construction guidance program in Shandong Province, and actively promotes the idea of resource development. A total of 5 papers were published, and the results were summarized and promoted. These results are publicized and reported in a variety of ways within the school. The people's daily press has given a high degree of evaluation to the train of thought for the publication of the textbook, and actively invited our college to publish it in the form of the characteristic textbook. The director of the project has been invited many times to speak in Dongying building construction professional vocational education alliance founding conference and Dongying Kenli vocational secondary professional school and participate in the conference on teaching reform and textbook construction. Binzhou TV station and Zouping county TV station publicize and report on the construction of teaching staff of construction engineering specialty, and the achievement and experience of student skills competition. Heze Juancheng vocational secondary school; Heze Yuncheng vocational secondary school; Liaocheng senior engineering vocational school; Pingdu vocational secondary school; Zibo construction engineering school; Dongying Kenli vocational secondary school and other schools came to our school for inspection and study. They came to learn and exchange architectural CAD skills competition, brand professional construction, spring college entrance examination skills competition and so on.

\section{Conclusion}

This achievement is highly targeted and systematic for construction engineering s. pecialty. It has made significant strides in the reform of education and teaching occupation, effectively promoting the development of occupation education, and improving the quality of personnel training There is a general promotion value, providing a model for the construction of professional teaching resource development and construction. This achievement has a strong effect on the periphery of the vocational colleges. There are 12 higher vocational colleges inside and outside the province adopted the results and the teaching effect is good. In the future, we will continue to make efforts from the following aspects: the teaching team follows the development of the network information technology and develops the information ability. We will take the students' learning activities as the center and make use of information intelligent software to make "Gamification" teaching resources and improve the teaching effect online and offline.

\section{Acknowledgements}

Research and practice of training model of professional personnel in higher vocational engineering under modern apprenticeship (ZJXH2017202)

\section{Refrences}

[1] Shuzhen Lv. Research on the professional teaching resources library Co-constructed by Collegeand Enterprise under the background of Digital Campus -- Taking the Major of construction engineering technology as an example[J]. Educational Observation (Middle and late issue). 2015 
[2] Jikui Qian, Bang Jin, Xiaomei Wang. Research on connotative development of Higher Vocational Education under the background of industrial transformation and Upgrading -- Taking the practice of connotative development of Higher Vocational Education in Jiangsu as an example[J]. Vocational and Technical Education. 2013(26)

[3] Zhi Chen. The mode, effect and prospect of the construction of virtual teaching platform for law[J]. Research on Law Education.2017

[4] Peng Zhang. Research on online virtual simulation training platform based on building teaching resource repository of Building Decoration Specialty[J]. Building Materials and Decoration. 2017

[5] Shiqin Hu, Wanlong Tang, Jun Zhang. Development, construction and research of teaching resource library for network course of "Construction of water supply and drainage engineering in building district” [J]. Out of school education in China. 2017

[6] Yongzheng Wang. Research on the integration of information technology and teaching in Civil Engineering Specialty in Higher Vocational Colleges[J]. Education and Teaching Forum. 2016,(2)

[7] Jing Xu. Research Report on construction of digitalized teaching resources in Secondary Vocational Schools. Brand[J]. 2015(1)

[8] Furui Yu. Exploration on teaching reform of Architectural Engineering Technology Specialty in Higher Vocational Colleges[D]. Shandong University. 2014(16)

[9] Li Wang. Talking about Curriculum reform of "building decoration construction organization and management” [J]. Education in Jilin. 2017

[10] Bin Yi. Independent research and development of simulation teaching aids and models for architectural engineering majors in Higher Vocational Colleges[J]. Education in Guangxi. 2015

[11] The Ministry of Education issued "the ten year development plan of education informatization (2011-2020)”[J]. Education information in China. 2012

[12] Xia Zhao, Xiuyan Zhang, Huiqin Yang. Research and practice of teaching platform construction for civil engineering majors in Higher Vocational Colleges[J]. Journal of Binzhou Polytechnic. 2014 